\title{
Effect of Time and Temperature on the Aging of 791-H SBS Modifier
}

\author{
Christian Magloire Ndjegwes ${ }^{1}$, Mouhamed Bayane Bouraima ${ }^{1}$, Xiao-hua Zhang ${ }^{2}$, Martin Bitolog ${ }^{1}$ and Yanjun Qiu ${ }^{1}$ \\ ${ }^{1}$ School of Civil Engineering, Southwest Jiaotong Univ., Highway Engineering Key Laboratory of Sichuan Province, Chengdu China. \\ ${ }^{2}$ Sichuan Provincial Transport Department Highway Planning, Survey, Design and Research Institute, Chengdu China.
}

\begin{abstract}
The effects of time and temperature level on the aging of the 791-H SBS modifier have been investigated through experimental study. A series of Thin Film Oven (TFO) Test was conducted at the temperature of $100^{\circ} \mathrm{C}$ and $163^{\circ} \mathrm{C}$ and time of 1,2, 5 and 10h. The changes in the chemical composition due to oxidative aging are detected by Fourier Transform Infrared Spectroscopy (FTIR) test. The results show that the visual observation of SBS after aging within 10h is almost unchanged when the aging temperature is $100^{\circ} \mathrm{C}$. At $163^{\circ} \mathrm{C}$ within $1-2 \mathrm{~h}$ aging, the SBS particles gradually softened and become slightly bonded to each other; at the same temperature after $5 \mathrm{~h}$ of aging, the particles of SBS became yellow. The result from FTIR test shows that temperature is an important factor in the aging of SBS modifier and its effect on the aging of SBS modifier is much greater than that of aging time.
\end{abstract}

\section{Introduction}

The term aging has been related to multiple mechanisms in asphalt mixtures. For some researchers, it indicates the overall deterioration of bitumen pavements, thus seriously affecting the performance and service life of asphalt pavement [1-6]. While in others cases, it is defined as a series of changes in asphalt concrete such as evaporation, oxidation, polymerization, and even the variations of the internal structure of asphalt [7]. Aging is also due to thermal aging and ultraviolet radiation aging [8,9], oxidative aging and moisture related damage [10]. Others researchers [11-12] showed that a series of physical and chemical variations took place under the action of natural conditions such as wind and rain, change of temperature during the storing, processing, construction, use of asphalt and because of exposure to the air. In addition to the increase of functional groups having oxygen, the other chemical composition of asphalt also changed which leads to its hardening, crisping and cracking. However, it couldn't keep on exerting the intrinsic cohesive and seal functions [13]. According to the study in [14], aging is defined as the irreversible changes of colloid structure, physical and chemical properties, or mechanical performance that asphalt had exhibited. The effect of extraction residue on the properties of asphalt binders has been investigated and results showed that ageing asphalt binder is related to extraction residue even is less sensitive [15]. The aging research of SBS modified asphalt has been increased and gradually aroused people's recognition with its increasing application $[16,17]$. The road surface's span life is influenced by the quality (good or bad) of the anti-aging performance of SBS modified asphalt. More study on aging has been done using basic asphalt in the past, but that of SBS modified asphalt has been less investigated. In 2011, the Sichuan Provincial Department of Communications and
Transportation issued the notice on improving the performance (rutting resistance) of expressway asphalt pavement (Letter of Sichuan [2011] No. 37). Modified asphalt has been widely used in the surface and middle layers of asphalt pavement in the local highway and the regeneration of modified asphalt mixture as it is the main material for the regeneration of the asphalt pavement in the province. In this study, the aging test of SBS modifier agent under different time and temperature is investigated in the thin film oven test. The effects of time and temperature on the aging of the commonly 791-H SBS modifier produced by Yueyang Petrochemical Company are also detected by means of infrared spectrum analysis.

\section{Experimental program}

\subsection{Materials}

In the experiment, the 791-H SBS that Yueyang petrochemical company produced as the modifier is used and shown in Figure 1. The general properties are shown in Table 1.

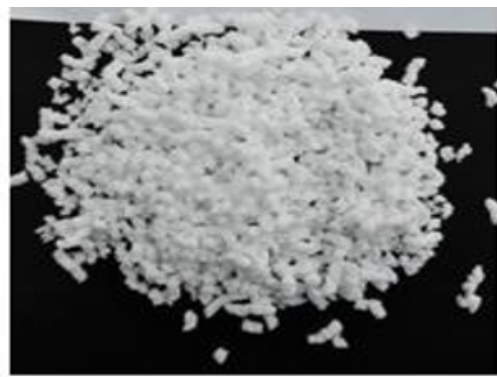

Figure 1. 791-H SBS modifier 
Table 1 Property of 791-H SBS

\begin{tabular}{cc}
\hline Composition & SBS \\
\hline Molecular structure & Linear \\
Block ratio- $(\mathrm{S} / \mathrm{B})$ & $30 / 70$ \\
Oil-extended content $(\%)$ & 0 \\
Volatile content $(\%)$ & 0.7 \\
Ash $(\%)$ & 0.5 \\
$300 \%$ tensile modulus $(\geqslant \mathrm{MPa})$ & 2 \\
Tensile strength & 18 \\
Elongation at break $(\leqslant \%) \%)$ & 750 \\
Residual deformation $(\leqslant \%)$ & 30 \\
Shore hardness $(\mathrm{A})$ & 75 \\
Melt flow rate $(\mathrm{g} / 10 \mathrm{~min})$ & 0.50 \\
\hline
\end{tabular}

\subsection{Methods}

The effect of temperature level and exposure time of 791-H SBS modifier has been investigated through experimental study. A series of Rolling Thin Film Oven (TFO) Test was conducted at the temperature for $100^{\circ} \mathrm{C}$ and $163^{\circ} \mathrm{C}$ and times for $1,2,5$ and $10 \mathrm{~h}$.

\section{Test results and discussion}

\subsection{SBS aging test}

The effects of aging temperature and aging time on SBS were investigated. The visual observation of SBS after aging is shown in Figure 2.

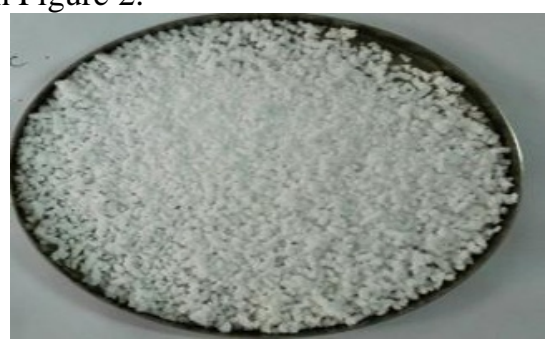

(a) Aging temperature: $100 \mathrm{C}$; aging time: $1 \mathrm{~h}$

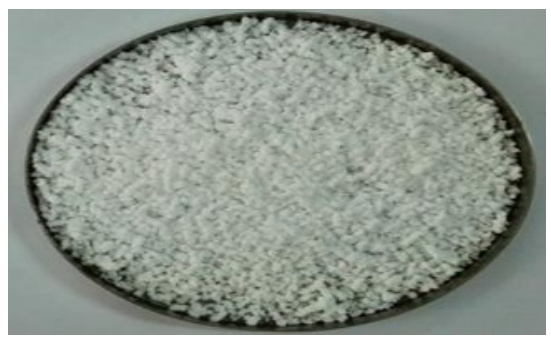

(b) Aging temperature: $100^{\circ} \mathrm{C}$; aging time: $2 \mathrm{~h}$
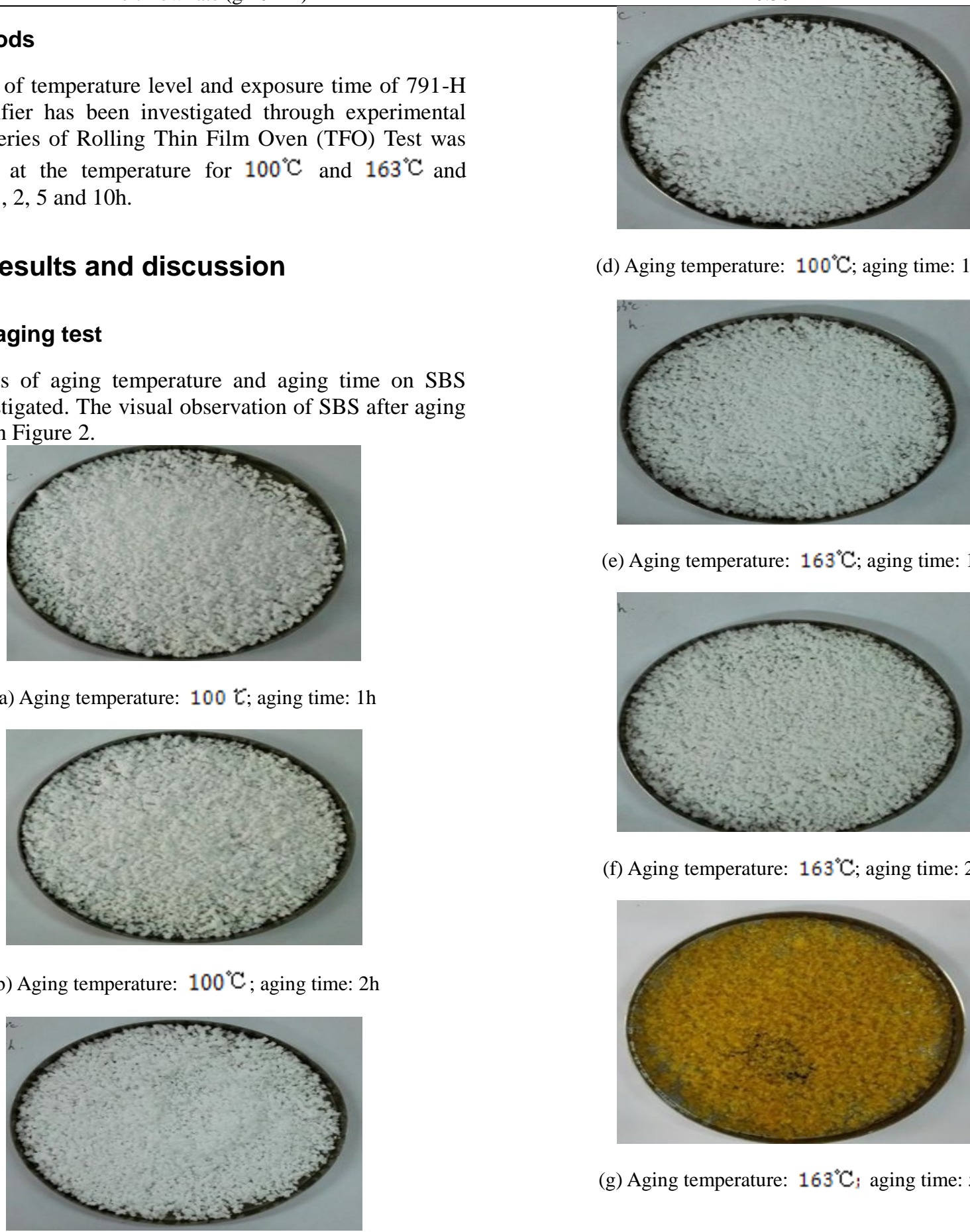

(d) Aging temperature: $100^{\circ} \mathrm{C}$; aging time: $10 \mathrm{~h}$

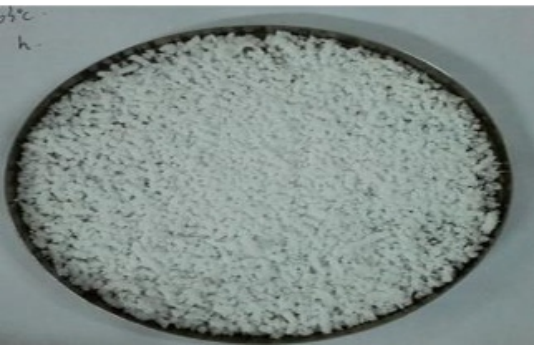

(e) Aging temperature: $163^{\circ} \mathrm{C}$; aging time: $1 \mathrm{~h}$

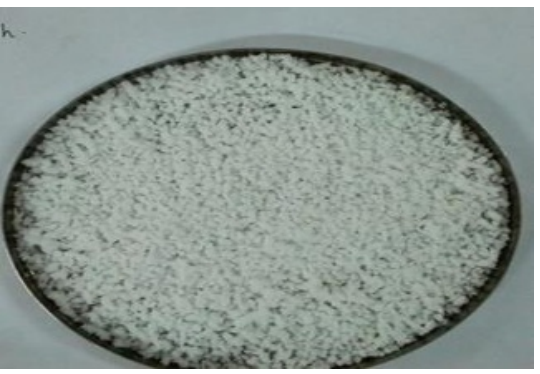

(f) Aging temperature: $163^{\circ} \mathrm{C}$; aging time: $2 \mathrm{~h}$

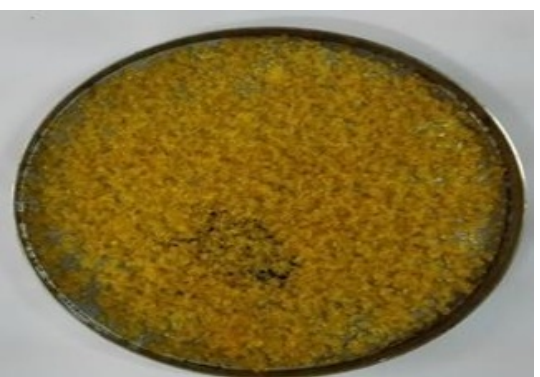

(g) Aging temperature: $163^{\circ} \mathrm{C}$; aging time: $5 \mathrm{~h}$

(c) Aging temperature: $100^{\circ} \mathrm{C}$; aging time: $5 \mathrm{~h}$ 


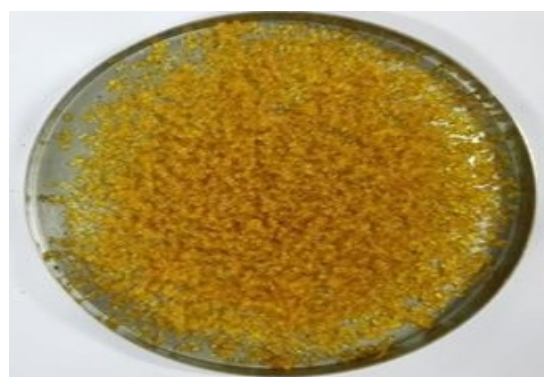

(h) Aging temperature: $163^{\circ} \mathrm{C}$; aging time: $10 \mathrm{~h}$

Figure 2. Visual observation of SBS after aging under different conditions

As can be seen from Figure 2, when the aging temperature is $100^{\circ} \mathrm{C}$, the visual observation of SBS after aging within $10 \mathrm{~h}$ is almost unchanged. When the temperature of the test was increased to $163^{\circ} \mathrm{C}$, the SBS particles gradually softened after $1 \sim 2 \mathrm{~h}$ aging and the particles were no longer in the dispersed state but were slightly bonded to each other. After aging for $5 \mathrm{~h}$, the particles of SBS became yellow, the particles are tightly bonded, and the SBS elasticity is gradually lost and converted into rigid plastic bodies. The change in mass of SBS at different aging times with temperature is shown in Table 2 .

\subsection{Infrared spectrum analysis of SBS after aging}

The SBS was analyzed by Fourier transform infrared spectroscopy before and after aging, and the change of SBS functional groups during aging was observed. The test instrument uses the Agilent Cary 630 FTIR model, the test results shown in Figure 4.

The descriptive analysis of the infrared spectrum results of the aged SBS at $100^{\circ} \mathrm{C}$ at $10 \mathrm{~h}$ from figure 5 (a) showed that there is no change with that of the original SBS and there is not the production of new functional groups during the process of $10 \mathrm{~h}$ aging at $100^{\circ} \mathrm{C}$. From figure $5(\mathrm{~b})$, it can be seen that there is still no change in the infrared spectrum results of SBS aging at $163^{\circ} \mathrm{C}$ within $1 \sim 2 \mathrm{~h}$ compared with the original SBS. After $5 \mathrm{~h}$ aging $\left(163^{\circ} \mathrm{C}\right)$, the infrared spectrum of SBS varies greatly and there are new absorption peaks at $3370 \mathrm{~cm}^{-1}$ and $1715 \mathrm{~cm}^{-1}$. The characteristic peak at $3370 \mathrm{~cm}^{-1}$ belongs to the characteristic absorption peak of $\mathrm{OH}$ while the characteristic peak at $1715 \mathrm{~cm}^{-1}$ belongs to the characteristic absorption peak of $\mathrm{C}=\mathrm{O}$. This indicated that after aging at $163^{\circ} \mathrm{C}$ for $5 \mathrm{~h}$, SBS had an oxygen reaction, and $\mathrm{OH}$ and $\mathrm{C}=\mathrm{O}$ functional groups appeared in the molecule. The result shows that temperature is an important factor in the aging of SBS modifier. The effect of temperature on the aging of SBS modifier is much greater than that of aging time. At $100^{\circ} \mathrm{C}$ under the conditions aging of $1 \mathrm{~h}$ to $10 \mathrm{~h}$, it can be shown that the performance was basically unchanged from the visual observation and infrared spectroscopy analysis. However, the performance at $163^{\circ} \mathrm{C}$ is more obvious, with the visual observation ce of yellow color at first and gradually deepened with time. The infrared spectrum analysis showed that oxygen reaction occurred in SBS.

Table 2 Change in mass of SBS quality different aging times

\begin{tabular}{|c|c|c|c|c|}
\hline \multirow{2}{*}{$\begin{array}{c}\text { Aging temperature } \\
{ }^{\circ} \mathrm{C}\end{array}$} & \multicolumn{4}{|c|}{ Mass changes at different aging times (\%) } \\
\cline { 2 - 5 } & $1 \mathrm{~h}$ & $2 \mathrm{~h}$ & $5 \mathrm{~h}$ & $10 \mathrm{~h}$ \\
\hline 100 & 0.2 & 0.2 & 0 & -0.4 \\
\hline 163 & -0.3 & -0.3 & 1.5 & 2.2 \\
\hline
\end{tabular}

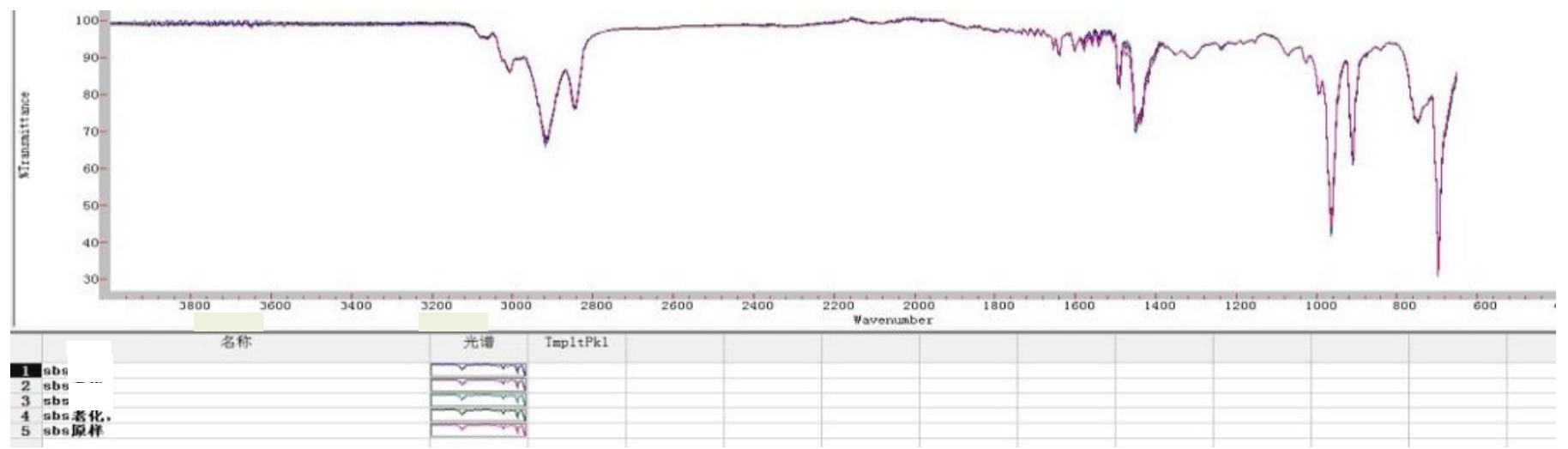

(a)Comparison of spectra of aged SBS at $100^{\circ} \mathrm{C}$ with original SBS at different time $1-100^{\circ} \mathrm{C}, 1 \mathrm{~h} ; 2-100^{\circ} \mathrm{C}, 2 \mathrm{~h} ; 3-100^{\circ} \mathrm{C}, 5 \mathrm{~h} ; 4-100^{\circ} \mathrm{C}, 10 \mathrm{~h}$; 5-original SBS 


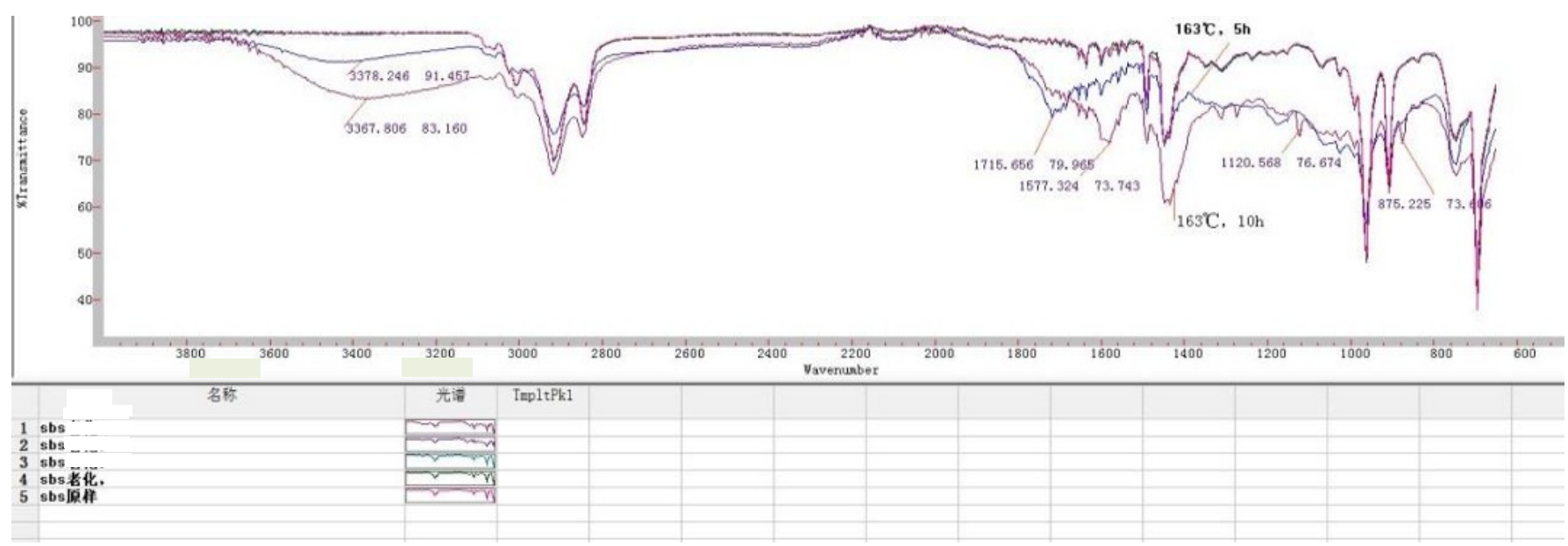

(b)Comparison of spectra of aged SBS at $163^{\circ} \mathrm{C}$ with original SBS at different time $1-163^{\circ} \mathrm{C}, 1 \mathrm{~h} ; 2-163^{\circ} \mathrm{C}, 2 \mathrm{~h} ; 3-163^{\circ} \mathrm{C}, 5 \mathrm{~h} ; 4-163^{\circ} \mathrm{C}, 10 \mathrm{~h} ; 5$ original SBS.

Figure 3. Infrared spectrogram of original SBS and SBS after aging.

\section{Conclusion}

The aim of this study is to investigate the effect of time and temperature on the aging of the 791-H SBS modifier by means of visual observation after Thin Film Oven (TFO) test and infrared spectrum analysis. The main conclusions drawn from the current research work are presented as follows:

- The visual observation of SBS after aging within $10 \mathrm{~h}$ is almost unchanged when the aging temperature is $100^{\circ} \mathrm{C}$

- $\quad$ At $163^{\circ} \mathrm{C}$ within $1-2 \mathrm{~h}$ aging, the SBS particles gradually softened and become slightly bonded to each other; at the same temperature degree after $5 \mathrm{~h}$ of aging, the particles of SBS became yellow.

- The temperature is an important factor in the aging of SBS modifier and its effect on the aging of SBS modifier is much greater than that of aging time.

\section{References}

1. Siddiqui, M. N., and Ali, M. F. "Studies on the aging behavior of the Arabian asphalts." Fuel (1999); 78(9), 1005-1015.

2. Mouillet, V., Farcas, F., and Besson, S. "Ageing by UV radiation of an elastomer modified bitumen." Fuel (2008); 87(12), 2408-2419.

3. Dehouche, N., Kaci, M., and Mokhtar, K. A. "Influence of thermo-oxidative aging on chemical composition and physical properties of polymer modified bitumens." Constr. Build. Mater.(2012); 26(1), 350-356.

4. Xiao, F., Punith, V., Amirkhanian, S., and Thodesen, C. "Improved resistance of long-term aged warm-mix asphalt to moisture damage containing moist aggregates.” J. Mater. Civ. Eng., (2013a); 10.1061/ (ASCE) MT.1943-5533.0000567, 913-922.

5. Chen, J., Chen, S., Liao, M., and Huang, S. "Laboratory evaluation of asphalt blends of recycling agents mixed with aged binders." J. Mater. Civ. Eng., (2015); 10.1061(ASCE) MT.1943-5533.0001081, 04014143.6.

6. Cheolmin Baek, Benjamin Shane Underwood, Yongbaek Richard Kim. Effects of oxidative aging on asphalt mixtures properties. Transportation Research Record.
2012

7. Huang S C, Grimes W. Influence of aging temperature on rheological and chemical properties of asphalt binders [J]. Transportation Research Record, 2010, 2179(1): 39-48

8. $\mathrm{Lu} \mathrm{XH}$, Isacsson U. Effect of ageing on bitumen chemistry and rheology.Constr Build Mater (2002); 16:15-22.

9. Durrieu F, Farcas F, Mouillet V. The influence of UV aging of a styrene/butadiene/styrene modified bitumen: comparison between laboratory and on site aging. Fuel(2007); 86:1446-51.

10. Wright, J.R. Weathering: Theoretical and Practical Aspects of Asphalt Durability. Chapter 8 in Bituminous Materials: Asphalts, Tars and Pitches Volume II, Ed. A.J. Hoiberg, Inter-science Publishers, New York, 1965.

11. EngineYener, Sinan Hinıslığlu. Effects of exposure time and temperature in aging test on asphalt binder properties. International Journal of Civil and Structural Engineering, volume 5, issue 2, 2014 Pages: 112 -124.

12. Engine Yener, Sinan Hinıslioğlu. The influence of the temperature and time variations on the aging of bituminous binders. 9th International Congress on Advances in Civil Engineering, 27-30 September 2010.

13. Yuan, J., and Zhao, K. (2000). The dose of modifier and the property of modified asphalt. Petrol. Asphalt 13:10.

14. Pan, Jielin. "A study of Asphalt Aging Behavior using Molecular Dynamics Simulations." (2016). http://digitalrepository.unm.edu/ ce_etds/12.

15. Bouraima, Mouhamed Bayane, Xiao-hua Zhang, Shui-wen Zhou, and Yanjun Qiu. "Effect of Extraction Residue on the Properties of Asphalt Binders." The Global Journal of Researches in Engineering. Vol 17, No 2-E (2017).

16. Y. Gao, F. Gu, L.Y. Zhang. Thermal oxidative aging characterization of SBS modified asphalt. J. Wuhan Univ. Technol., 2 (2013), pp. 88-91

17. F. Zhang, J. Y. Yu, S. P. Wu. Effect on ageing on rheological properties of storage-stable SBS/sulfur-modified asphalts. J. Hazard. Mater. 507-517 (2010). 